\title{
Nahal Yarmuth 38: a new and unique Pre-Pottery Neolithic B site in central Israel
}

Avi Gopher ${ }^{1, *}$, Anna Eirikh-Rose ${ }^{2}$, Hai Ashkenazi ${ }^{1}$, Eyal Marco ${ }^{2}$, Hila May ${ }^{3,4}$, Yulia Makoviychuk ${ }^{1,4}$, Lidar Sapir-Hen ${ }^{1,6}$, Shirad Galmor ${ }^{1}$, Heeli C. Schechter ${ }^{5}$, Dana Ackerfeld ${ }^{1}$, Gil Haklay ${ }^{1,2} \&$ Katia Zutovski $^{1}$

The small, Middle Pre-Pottery Neolithic B site (tenth millennium cal BP) of Nahal Yarmuth 38 in central Israel consists of a unique series of rectilinear structures with plastered floors, beneath which multiple interments were found. The nature of the finds combined with existing knowledge of burial customs of this period make Nahal Yarmuth 38 an ideal site for investigating designated burial sites in the Middle Pre-Pottery Neolithic B.

Keywords: Israel, Pre-Pottery Neolithic B, burial, Neolithisation

Nahal Yarmuth 38 is located in central Israel between Tel Aviv and Jerusalem, some $34 \mathrm{~km}$ from the Mediterranean coast (Figure 1). Extensive excavations by a joint Tel Aviv University-Israel Antiquities Authority team in 2017-2018 exposed an area of $700 \mathrm{~m}^{2}$ (Figure 2). The stratigraphy consisted of a Pre-Pottery Neolithic B layer overlying bedrock and a later, partially overlapping, Pottery Neolithic layer. The area is unusually small (0.1-0.2ha) and provides a glimpse into a uniquely structured Pre-Pottery Neolithic B site with two major arrays of interrelated features: architecture, mostly lime-plastered rectilinear structures, and human burials, found mainly under lime-plastered floors.

Five structures were revealed, four of them relatively complete in plan (Figure 2). These were originally undivided square structures measuring $5 \times 5 \mathrm{~m}$ to $6.5 \times 6.5 \mathrm{~m}$. The stone walls are $0.6-0.8 \mathrm{~m}$ thick, preserved to an elevation of up to $0.4 \mathrm{~m}$ in one to three courses of undressed stone. Only a small number of fallen stones were found near the structures, indicating that these stone walls had not been considerably higher. Of note are two minor changes

1 Institute of Archaeology, Tel Aviv University, P.O. Box 39040, Tel Aviv 6997801, Israel

2 Israel Antiquities Authority, Rockefeller Museum, Sultan Suleiman, Jerusalem, Israel

3 Department of Anatomy and Anthropology, Sackler Faculty of Medicine, Tel Aviv University, Tel Aviv 6997801, Israel

4 Shmunis Family Anthropology Institute, The Dan David Center for Human Evolution and Biohistory Research, Sackler Faculty of Medicine and the Steinhardt Museum of Natural History, Tel Aviv University, Tel Aviv 6997801, Israel

5 Institute of Archaeology and Jack, Joseph and Morton Mandel School for Advanced Studies in the Humanities, Hebrew University of Jerusalem, Jerusalem, Israel

6 Steinhardt Museum of Natural History, Tel Aviv University, Tel Aviv 6997801, Israel

* Author for correspondence (Email: agopher@tauex.tau.ac.il)

(C) Antiquity Publications Ltd, 2019

ANTIQUITY 93 371, e29 (2019): 1-8

https://doi.org/10.15184/aqy.2019.162 


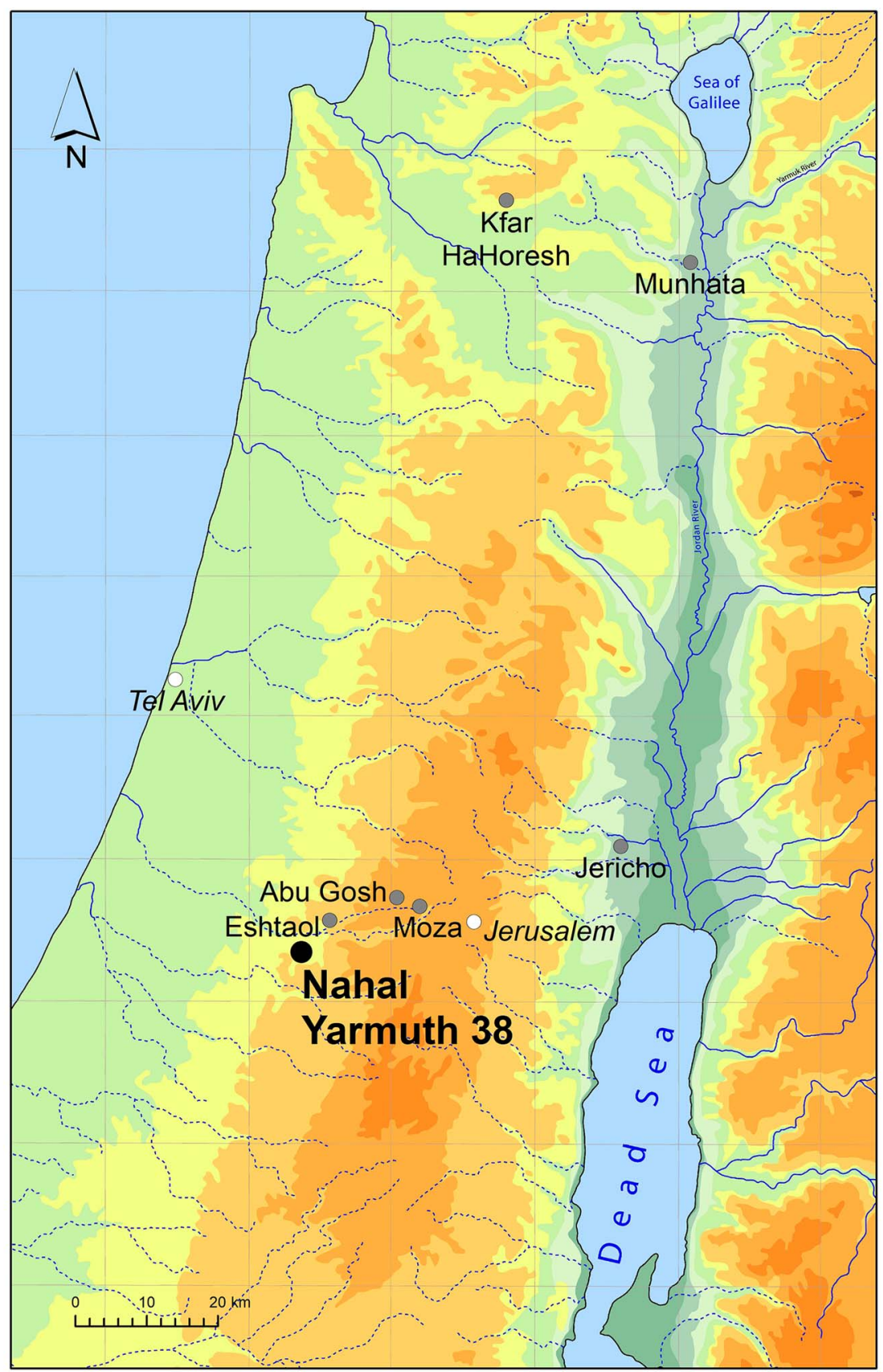

Figure 1. Location map showing the Neolithic sites mentioned in text (figure by Itamar Ben Ezra).

in wall orientation between subsequent phases in structures I and V. Lime plaster covers the entire floor area, rising slightly where it meets the walls. The lime plaster itself is $30-150 \mathrm{~mm}$ thick and is laid on an infrastructure fill of fist-size angular stones, 30-300 mm in thickness, with up to six phases of repair evident in the same structure (Figure 3).

(C) Antiquity Publications Ltd, 2019 


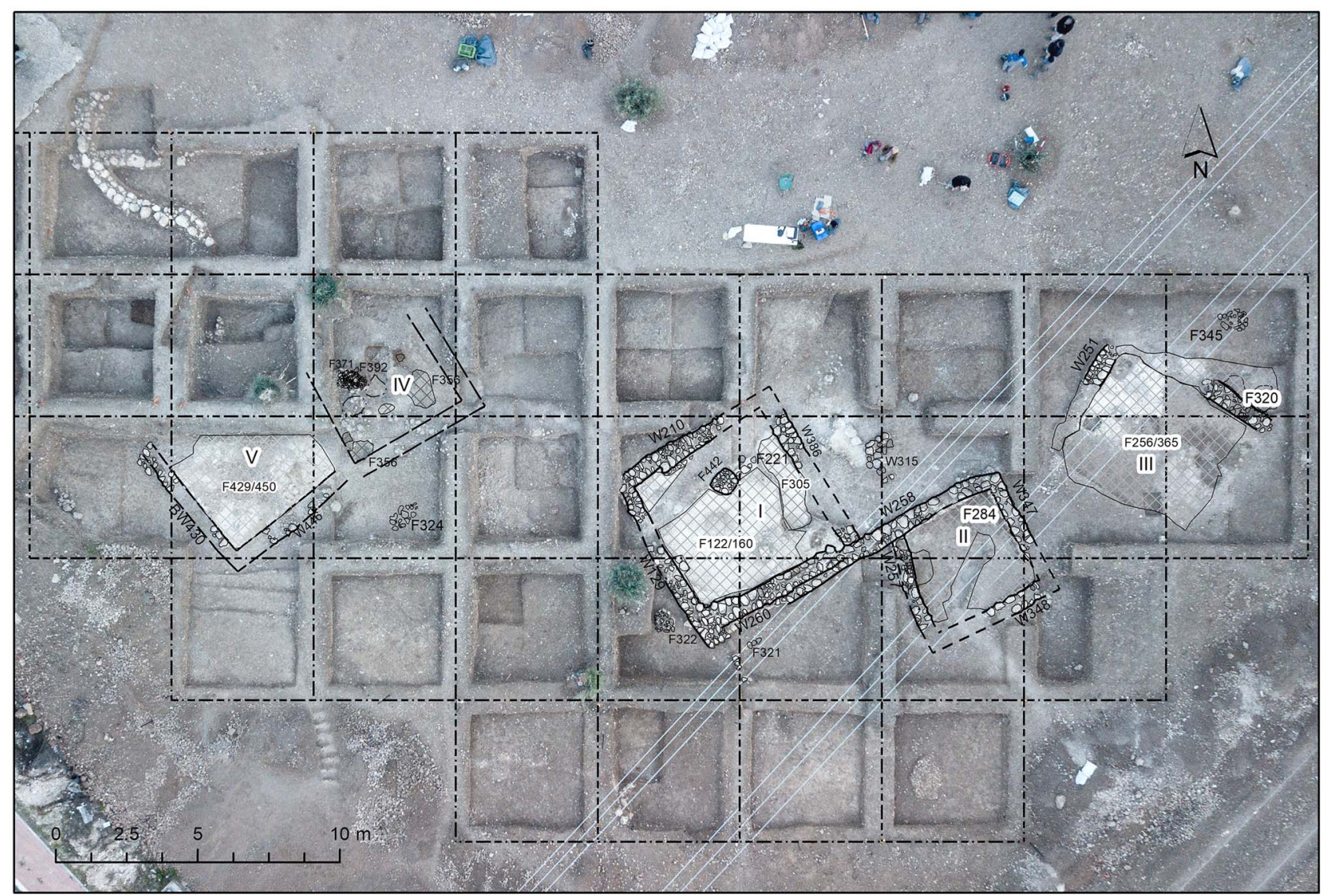

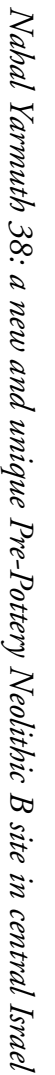

F Figure 2. Aerial photograph of the excavation showing the lime-plastered structures (oval structure at the top left belongs to the later Pottery Neolithic layer) (photograph by Boaz Norss, graphics by Hai Ashkenazi).

\section{Project Gallery}




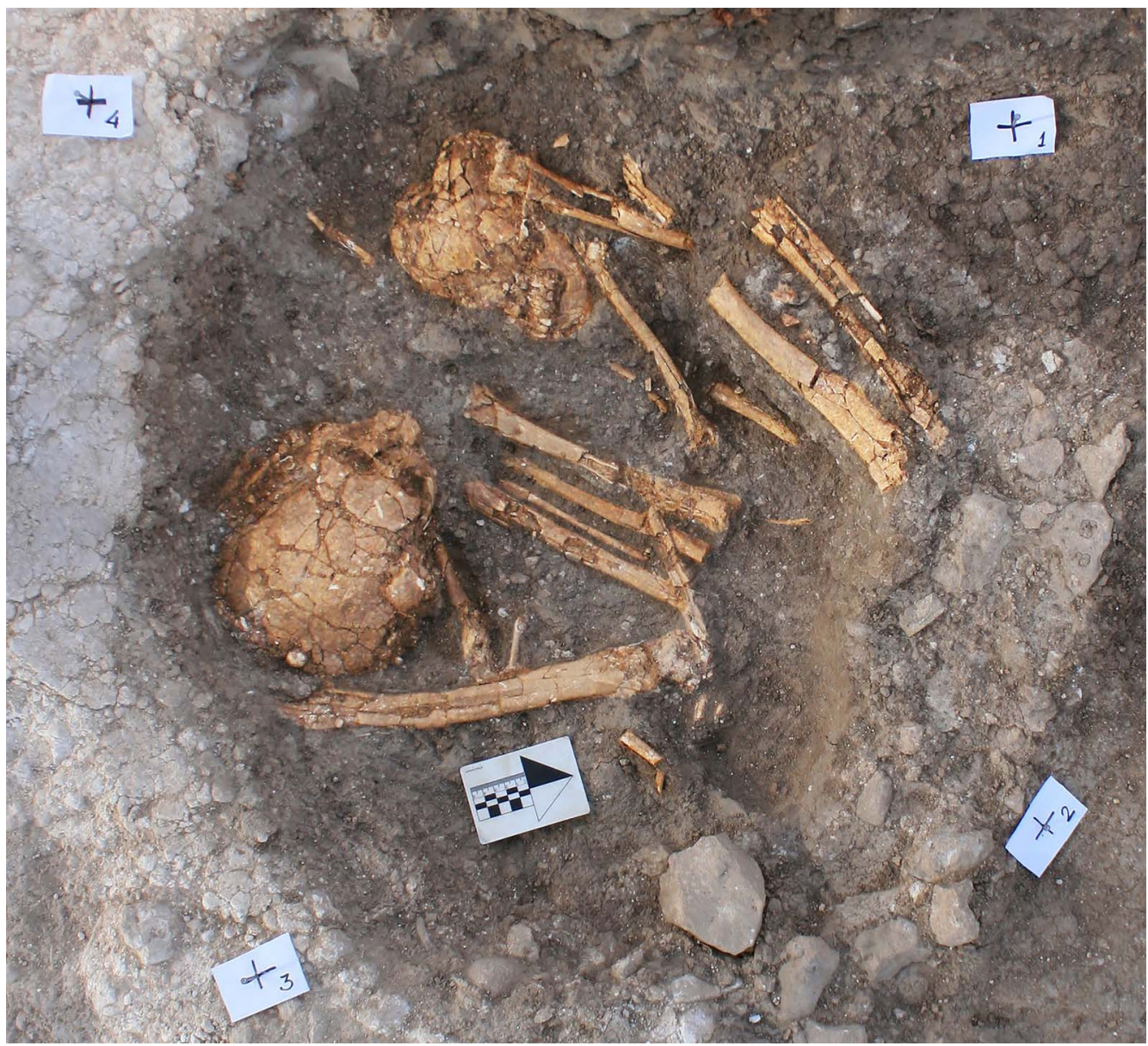

Figure 4. Multiple burial of two adult individuals facing each other, found under the plastered floor of structure III (photograph by Hai Ashkenazi).

Floors show signs of opening and reclosing, probably representing patching; some have sunken areas, often near the corners, and pits that cut the plaster covering. A raised feature, of an as yet unclear purpose and also plastered, was found in structure V (Figure 3). Floors have painted elements (red, black and yellow) in at least four of the five structures, but no clear patterns could be identified. Plastered floors were generally 'clean', with almost no finds apart from single flint items and, rarely, a burial that post-dated the floor and was laid on top of it.

Based on an on-going restoration of the skeletal remains, a minimum number of almost 40 individuals related to the Pre-Pottery Neolithic B layer were excavated. The majority were primary, single adult burials. Three multiple burials included one with two adults in flexed position facing each other (Figure 4), and two with adults and a child or baby. All individuals were in a flexed or semi-flexed position, except for one single burial of a child in a sitting position. The presence of children in this sample was limited. Skulls were missing in several of the burials, and only a few burials had grave goods; those that did included marine shells, 


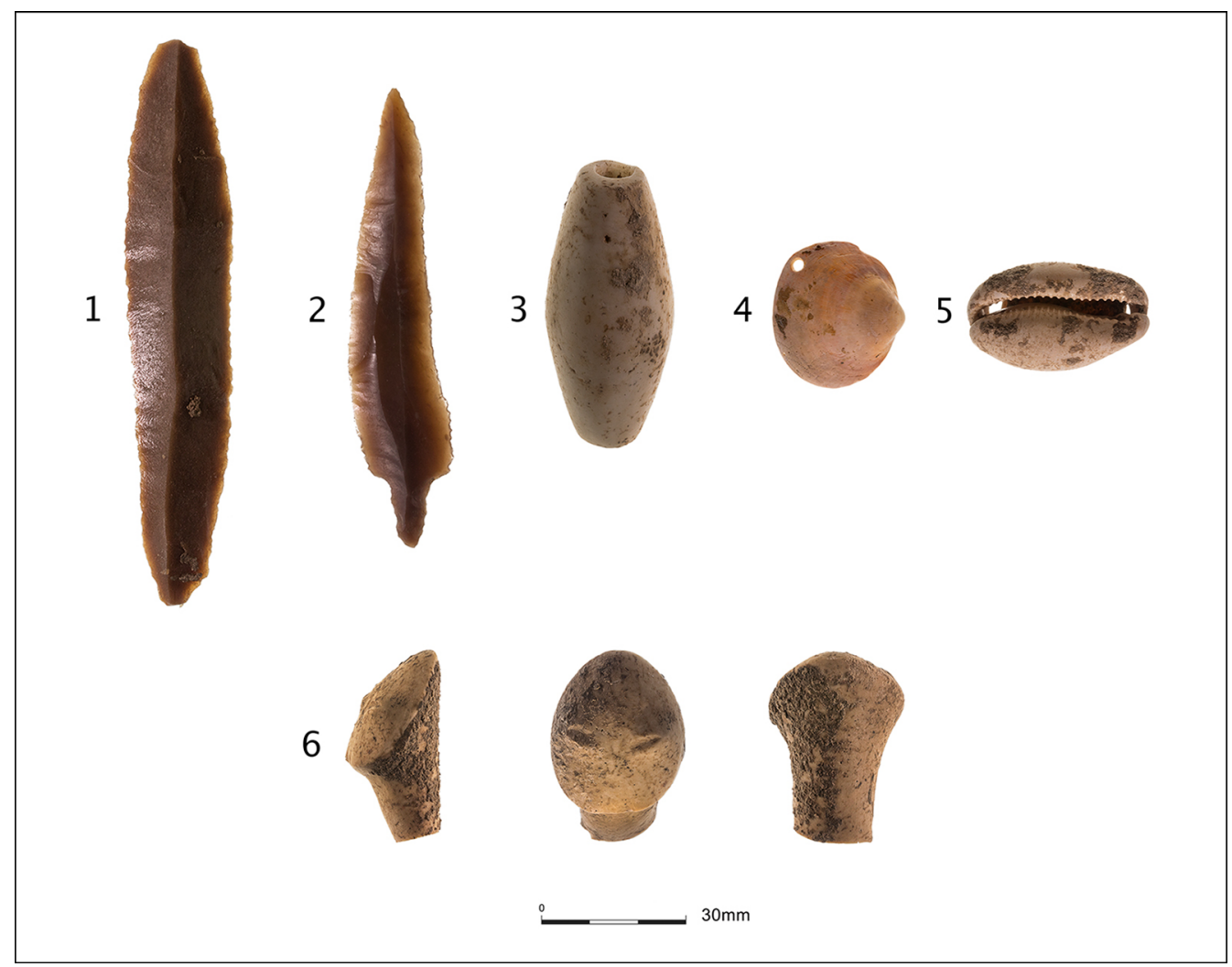

Figure 5. 1) Sickle blade (notice the sheen on the left side); 2) arrowhead; 3) stone pendant; 4-5) marine shells; 6) anthropomorphic stone figure (photographs by Sasha Flit).

flint tools (e.g. arrowheads), beads, and in one case an anthropomorphic stone figure. Animal bones were either near to burials or, in a few cases, directly associated with them.

The Pre-Pottery Neolithic B lithics are of high-quality, colourful raw materials and while bidirectionally knapped blades are present, no such cores (or related core-trimming elements) were noted. The assemblage includes typical Middle Pre-Pottery Neolithic B arrowheads of the Jericho and Byblos types and classical, finely denticulated sickle blades (Figure 5.1-2). Bifacial tools are notably absent. Large, passive grinding slabs, some active processors and a few stone cutting boards were found, as well as a broken gaming board. Bone points and spatula were found along with stone pendants (Figure 5.3), a variety of stone beads, cylindrical bone beads and worked marine shells, some of which were related to burials (Figure 5.4-5). A single anthropomorphic stone figure was also found (Figure 5.6).

Faunal remains mainly include wild goat (Capra aegagrus) and mountain gazelle (Gazella gazella). Auroch (Bos primigenius) and wild boar (Sus scrofa) are found in lower frequencies as well as Persian fallow deer (Dama mesopotamica) and red fox (Vulpes vulpes). Shells are especially abundant (many hundreds) deriving from land, freshwater and marine environments. 
Mediterranean bivalves dominate the marine shells assemblage, although gastropods and Red Sea shells are also included. Artificially manipulated shells are scarce. These characteristics are typical of Neolithic sites in the Mediterranean zone of Israel.

Radiocarbon dating is under way; meanwhile, based on the plastered features at the site and the lithic techno-typology, Nahal Yarmuth 38 is assigned to the Middle Pre-Pottery Neolithic B. It joins the larger Pre-Pottery Neolithic B interaction sphere of the Levant along with known regional sites of the same period such as Motza, Abu Gosh, Eshtaol and other surveyed sites (Khalaily \& Marder 2003; Khalaily et al. 2007; Vardi et al. 2016; see Figure 1).

While exhibiting some residential material elements, Nahal Yarmuth 38 comprises elements that may support its interpretation as a designated Middle Pre-Pottery Neolithic B burial site. These include: small site size and the high concentration of burials related to the lime-plastered structures that show no evidence of superstructures above the low stone walls; the dominance of buried adults reflects limited population representation, while the whole population is typically represented in Pre-Pottery Neolithic B residential sites; the scarce evidence of onsite production (especially of flint tools), and the lack of clear evidence for an active residential site (e.g. fireplaces and refuse pits).

The Pre-Pottery Neolithic B site of Kfar HaHoresh in the Lower Galilee, studied intensively in the last two decades (Goring-Morris 2005; Birkenfeld 2018), was presented as a designated burial site of that period. Although detailed results for Nahal Yarmuth 38 are still awaited, the evidence presented here surely merits its inclusion in discussions of designated burial sites in the Pre-Pottery Neolithic B. Such burial sites may reflect one of the perceptual and socio-economic developments that characterise the Neolithic Revolution. Designated Pre-Pottery Neolithic B burial sites may broaden our understanding of the contexts and circumstances of Neolithisation processes and contribute to discourse on the role of the dead in the daily life of Levantine communities from the Epipalaeolithic Natufian (c. 15 000-12 $000 \mathrm{cal} \mathrm{BP)}$ to the Chalcolithic period (6500-5800 cal BP).

\section{Acknowledgements}

We would like to thank: the staff of the Israeli Institute of Archaeology_Boaz Gross, Omer Zeevi, George Mavronanos and Alon Shavit; field supervisors and staff members-Adi Rotem, Talia Atali, Yafit Kedar, Bar Efrati and Yoni Parush; the Israel Antiquities Authority for support and good will. We thank the Israeli Ministry of Science, Technology and Space for financial support for K. Zutovski's scholarship. We also thank Hadas Avni, Samuel Francis, Ariel Pokhojaev, Viktoria Roul and Sarah Borgel who excavated the skeletons. We thank our scientific partners Israel Hershkovitz, Elizabetta Boaretto, Johanna Regev, Yotam Asher, Daphna Langgut, Oren Ackerman and Daniella Bar-Yosef. Fieldwork photographs are by staff members and we thank Sasha Flit, of Tel Aviv University, for studio photography.

\section{References}

Birkenfeld, M. 2018. Changing systems: Pre-Pottery Neolithic B settlement patterns in the Lower Galilee, Israel. Berlin: Ex-oriente.

Goring-Morris, A.N. 2005. Life, death and the emergence of differential status in the Near
Eastern Neolithic: evidence from Kfar HaHoresh, Lower Galilee, Israel, in J. Clarke (ed.) Archaeological perspectives on the transmission and transformation of culture in the Eastern Mediterranean: 89-105. Oxford: Oxbow.

Khalaily, H. \& O. Marder. 2003. The Neolithic site of Abu Gosh, the 1995 excavations (Israel 
Antiquities Authority Reports 19). Jerusalem: Israel Antiquities Authority.

Khalaily, H. et al. 2007. Excavations at Motza in the Judean Hills and the early Pre-Pottery Neolithic B in the southern Levant. Paléorient 33(2): 5-37. https://doi.org/10.3406/paleo.2007.5218

VARDI, J. et al. 2016. The Neolithic site of Eshta'ol. Poster. Israel Antiquities Authority.

Received: 1 April 2019; Revised: 17 June 2019; Accepted: 21 June 2019

(C) Antiquity Publications Ltd, 2019 